\title{
Consumo e digestibilidade do feno de capim-braquiária em bovinos de corte sob suplementação com mistura contendo sulfato de amônio, caseína e uréia ${ }^{1}$
}

\author{
Luiz Henrique Gomes da Silva de Rezende ${ }^{2}$, Tiago Zanetti Albertini², Edenio Detmann ${ }^{3}$, \\ Thierry Ribeiro Tomich ${ }^{4}$, Gumercindo Loriano Franco ${ }^{5}$, Beatriz Lempp ${ }^{5}$, Maria da Graça Morais ${ }^{5}$ \\ 1 Projeto financiado pela Fundect e CNPq. \\ ${ }^{2}$ Curso de graduação em Medicina Veterinária - UFMS. \\ ${ }^{3}$ Departamento Zootecnia - UFV. \\ 4 Embrapa Pantanal. \\ ${ }^{5}$ Departamento de Produção Animal - UFMS.
}

RESUMO - Avaliaram-se o consumo e a digestibilidade dos nutrientes de dietas contendo feno de capim-braquiária (Brachiaria brizantha cv. MG4) de baixa qualidade e de diferentes níveis protéicos. Os tratamentos avaliados foram: controle (somente feno) e feno com adição crescente, via infusão ruminal, da mistura sulfato de amônio, caseína e uréia (0,5:1,0:4,5) de modo a elevar em $+2,+4$, +6 e $+8 \%$ o nível de PB das dietas. Os dados foram analisados em delineamento quadrado latino, com cinco níveis de suplementação, cinco animais e cinco períodos. A adição de quantidades crescentes de nitrogênio nãoprotéico (NNP) à dieta teve efeito quadrático sobre os consumos de matéria seca (MS), matéria orgânica (MO), fibra em detergente neutro (FDN) e extrato etéreo (EE). O maior consumo de MS foi observado com o nível de 10,5\% PB. Não foram observados efeitos dos níveis de PB sobre os coeficientes de digestibilidade de MS, MO, FDN e EE. Houve efeito linear crescente sobre o coeficiente de digestibilidade da PB, que apresentou valores de 57,4; 66,9; 73,6; 77,3 e 81,7\% nos níveis de PB de 6,3; 8,5; 10,5; 12,63 e 14,8\%, respectivamente. O nível de 10,5\% de PB foi o ponto crítico para a obtenção de resposta máxima para os consumos de MS (7,7 kg/dia) e MO (7,2 kg/dia). A suplementação com compostos nitrogenados em quantidades que permitam elevar o nível protéico da dieta a 10,5\% otimiza o uso de forragens de baixa qualidade.

Palavras-chave: digestibilidade aparente, forragem de baixa qualidade, ingestão, nitrogênio não-protéico

\section{Intake and digestibility of palisade grass hay by beef cattle supplemented with a mixture containing ammonium sulphate, casein and urea}

\begin{abstract}
The intake and digestibilility of the nutrients of diets containing palisade grass (Brachiaria brizantha cv MG4) hay of low quality and different protein levels were evaluated. The evaluated treatments were control (only hay) and hay with crescent addition, by rumen infusion, of the mixture containing ammonium sulphate, casein end urea (0.5:1.0:4.5) in way to elevate in $+2,+4,+6$ and $+8 \%$ the $\mathrm{CP}$ level in the diets. A Latin square experimental design with five levels supplementation, five animals and five periods was used. The addition of crescent levels of no protein nitrogen (NPN) to the diet showed a quadratic effect on the dry matter (DM), organic matter (OM), neutral detergent fiber (NDF) and ether extract (EE) intake, and the biggest intake was observed with level of $10.5 \%$ CP. No effect of CP levels were observed for on the DM, OM, NDF and EE digestibilities coefficients. There was crescent linear effect on CP apparent digestibility coefficient, that showed values of $57.4,66.9,73.6,77.3$ and $81.7 \%$ for the CP levels of $6.3,8.5,10.5,12.6$ and $14.8 \%$, respectively. The critical point and estimated maximum response were: $10.5 \% \mathrm{CP}$ and $7.7 \mathrm{~kg}$ DM/day and $7.2 \mathrm{~kg} \mathrm{OM} /$ day. The supplementation with nitrogenous compounds in amounts that permit to elevate the dietary protein level up to $10.5 \%$ of $\mathrm{CP}$ increases the use of low-quality forage.
\end{abstract}

Key Words: apparent digestibility, intake, low-quality forage, non-protein nitrogen

\section{Introdução}

O Brasil Central possui um sistema de produção de gado de corte baseado principalmente no manejo extensivo, no qual a alimentação se baseia em sistemas pastoris. Todavia, a produtividade dos animais submetidos a esse manejo apresenta elevada variação, em decorrência da menor produção e qualidade ocasionada pela escassez de forragem no período seco. Euclides (1997), acompanhando o efeito climático sobre o valor nutricional de Brachiaria brizantha cv. Marandu, observou que o teor de proteína bruta (PB) e a digestibilidade in vitro da matéria orgânica 
diminuíram de 9,3 e $61,2 \%$ para 6,2 e 51,5\%, respectivamente, do período chuvoso para o período seco do ano.

Pastos tropicais e subtropicais são caracterizados por rápida taxa de crescimento durante o período chuvoso e, quando bem manejados, apresentam bom valor nutritivo. No início da estação seca, o pasto reduz o crescimento e a qualidade, o que pode levar à perda excessiva de peso dos animais, que constitui o principal fator limitante na produção animal a pasto (Leng, 1984).

Embora nessas condições múltiplas carências nutricionais (energia, proteína, fósforo etc) sejam descritas, a deficiência de compostos nitrogenados apresenta-se como prioritária (Paulino et al.,1982), o que implica condições subótimas no ambiente ruminal, (Ørskov, 2000), limitantes à atividade microbiana, à digestibilidade e ao consumo de forragem, o que pode acarretar baixo desempenho animal (Paulino, 1998). Segundo Egan \& Doyle (1985), bovinos alimentados com pasto de teor protéico inferior a 7\% são incapazes de manter o nível mínimo de $8 \mathrm{mg} / \mathrm{dL}$ de nitrogênio amoniacal necessário para manutenção do crescimento das bactérias celulolíticas, o que reduz sua atividade digestiva e o consumo de MS. A simples adição de níveis quantitativos de energia e nitrogênio prontamente solúveis é capaz de aumentar a digestão da forragem de baixa qualidade e, em alguns casos, aumentar o consumo, justamente por proporcionar efeito associativo positivo na digestibilidade da MS. Campos et al. (2002) avaliaram os efeitos da inclusão de fontes e de níveis concentrados sobre a digestibilidade da MS de capim-elefante cv. Napier e constataram que o efeito associativo positivo foi mais evidente para a forragem de baixa qualidade.

A utilização exclusiva de fontes de nitrogênio nãoprotéico (NNP), como a uréia ou amiréia, ou a substituição de parte da proteína verdadeira degradável por esses compostos em suplementos protéicos utilizados em pasto de baixa qualidade representam uma alternativa economicamente viável, uma vez que bactérias fermentadoras de carboidratos estruturais utilizam eficientemente o NNP contido na amônia como fonte nitrogenada (Russell et al., 1992).

Resultados de vários trabalhos têm comprovado os benefícios nutricionais e produtivos da suplementação nitrogenada em condições de baixa qualidade da forragem, entretanto, são escassos os resultados sobre a quantificação precisa das interações entre os compostos nitrogenados, o consumo voluntário e a dinâmica digestiva dos alimentos volumosos. Nesse contexto, realizou-se este trabalho com o objetivo de estudar as interações entre níveis crescentes de uréia e o consumo e a digestibilidade dos nutrientes do feno de Brachiaria brizantha cv. MG4 de baixo valor nutritivo.

\section{Material e Métodos}

O experimento foi realizado nas dependências do Núcleo de Ciências Veterinárias da Universidade Federal de Mato Grosso do Sul no período de janeiro a maio de 2004. Foram utilizados cinco novilhos da raça Nelore, com peso médio inicial de $370 \mathrm{~kg}$, portadores de cânula permanente no rúmen, alojados em baias individuais com água e mistura mineral à vontade durante todo o experimento.

Avaliou-se a suplementação de cinco níveis protéicos em dieta à base de feno de capim-braquiária (Brachiaria brizantha), cv. MG4, de baixa qualidade. O tratamento controle consistiu do fornecimento exclusivo do feno de capim-braquiária (controle) e os demais, da adição, via infusão ruminal, de quantidades crescentes de suplemento nitrogenado de modo a elevar gradativamente o nível de PB da dieta basal em intervalos de dois pontos percentuais, ou seja, $+2,+4,+6$ e $+8 \%$. O suplemento foi composto de mistura contendo uréia + sulfato de amônio e caseína nas proporções de 4,5:0,5:1,0, respectivamente (Tabela 1). O sulfato de amônio foi utilizado para fornecer enxofre (S) e nitrogênio e a caseína como substrato protéico e dos ácidos graxos de cadeia ramificada como fonte de energia, todos para garantir condições favoráveis para a fermentação ruminal dos animais.

O feno foi triturado e fornecido, em duas porções diárias de mesmo peso, às 8 e $20 \mathrm{~h}$, de modo a permitir aproximadamente $10 \%$ de sobras. O suplemento foi fracionado em três porções iguais e foram infundidos diretamente no rúmen dos animais às 8, 16 e 24 h. Foram utilizados cinco períodos experimentais de 12 dias de duração, de modo que sete dias foram destinados à adaptação dos animais à dieta e cinco à coleta de dados. Nos dois primeiros dias de cada período de adaptação, infundiu-se um terço da dose completa da mistura de uréia. No terceiro e quarto dias, utilizaram-se dois terços da dose completa da mistura de uréia e, no quinto, sexto e sétimo dias do período de adaptação, foi fornecida a dose completa da mistura de uréia. A quantidade do suplemento infundida diariamente foi calculada considerando o consumo de volumosos do dia anterior (Tabela 2). Utilizou-se o método de coleta total de fezes durante cinco dias consecutivos para determinação dos coeficientes de digestibilidade. Os animais foram monitorados durante 24 horas. A cada defecação, as fezes foram pesadas e amostradas (10\%) para formação de amostras individuais compostas, que foram congeladas para posteriores análises.

Amostras individuais compostas de fezes e de sobras foram pré-secas, moídas e analisadas quanto aos teores de matéria seca (MS), matéria orgânica (MO), proteína bruta 
Tabela 1 - Composição nutricional do feno de capim-braquiária) e da uréia

\begin{tabular}{lcccccccc}
\hline Ingrediente & \multicolumn{1}{l}{ Composição } & nutricional $(\%$ da & MS) & & \\
\hline & MS & PB & MO & FDN & FDA & CNF & EE & NDT $^{1}$ \\
\hline Feno & 91,59 & 6,30 & 93,71 & 82,03 & 49,73 & 4,59 & 1,41 & 39,2 \\
Uréia & 100,00 & 287,52 & - & - & - & - & - \\
\hline
\end{tabular}

$1 \%$ NDT $=91,6086-0,669233($ FDN $)+0,437932$ (PB) (Cappelle et al., 2001).

Tabela 2 - Teores médios de proteína bruta das dietas, quantidade diária fornecida de uréia, sulfato de amônio e caseína e percentual de uréia consumida na MS das dietas

\begin{tabular}{lrrrrr}
\hline Item & \multicolumn{5}{c}{ Nível de proteína bruta da dieta (\%) } \\
\cline { 2 - 6 } & 6,3 & 8,5 & 10,5 & 12,6 & 14,8 \\
\hline $\begin{array}{l}\text { Uréia (g/dia) } \\
\text { Sulfato de amônio } \\
\text { (g/dia) }\end{array}$ & 0,0 & 51,8 & 107,3 & 151,5 & 193,5 \\
Caseína (g/dia) & 0,0 & 12,0 & 24,0 & 34,0 & 43,0 \\
Uréia $^{1}$ & 0,0 & 0,7 & 1,4 & 2,1 & 2,8 \\
\hline
\end{tabular}

${ }^{1} \mathrm{Em} \%$ do consumo de matéria seca.

(PB), extrato etéreo (EE), fibra em detergente neutro (FDN) e fibra em detergente ácido (FDA), conforme descrito por Silva \& Queiroz (2002). Os dados foram analisados utilizando-se o programa Sistema para Análises Estatísticas e Genéticas (SAEG), de acordo com Ribeiro Jr. (2001). Empregou-se o delineamento experimental em quadrado latino, com disposição dos tratamentos às unidades experimentais de forma balanceada para efeitos residuais (Lucas, 1957), com cinco níveis de suplementação, cinco animais e cinco períodos, segundo o seguinte modelo estatístico:

$$
\mathrm{Y}_{\mathrm{ijk}}=\mu+\mathrm{T}_{\mathrm{i}}+\mathrm{A}_{\mathrm{j}}+\mathrm{P}_{\mathrm{k}}+\varepsilon_{\mathrm{ijk}} \text {, }
$$

em que $Y_{i j k}=$ observação relativa ao nível de suplementação $\mathrm{i}$, mensurada no animal $\mathrm{j}$ no período $\mathrm{k} ; \mu=$ constante; $\mathrm{T}_{\mathrm{i}}=$ efeito do nível de suplementação i $\left(j=1,2,3,4\right.$ e 5); $A_{j}=$ efeito do animal $\mathrm{j}\left(\mathrm{j}=1,2,3\right.$, 4 e 5); $\mathrm{P}_{\mathrm{k}}=$ efeito do período $\mathrm{k}$ $\left(\mathrm{k}=1,2\right.$, 3, 4 e 5); $\varepsilon_{\mathrm{ijk}}=$ erro aleatório associado a cada observação, presuposto $\operatorname{NID}\left(0 ; \sigma^{2}\right)$.

As comparações entre médias de níveis de proteína bruta foram realizadas pela decomposição da soma de quadrados relacionada a cada fonte de variação em contrastes ortogonais, conforme descrito por Steel et al. (1997), com posterior ajuste de equações de regressão linear, de acordo com Myers (1990).

\section{Resultados e Discussão}

As interpretações estatísticas das estimativas de consumo em relação aos teores de PB das dietas (Tabela 3) foram realizadas considerando os níveis médios de $\mathrm{PB}$ das dietas, produzidos por meio da razão entre o consumo total de PB (feno e suplemento) e o consumo total de MS. Os valores obtidos foram: 6,$3 ; 8,3 ; 10,5 ; 12,6$ e $14,8 \%$ de PB para as dietas controle, $+2 \%,+4 \%$, $+6 \%$ e $+8 \%$ de $P B$, respectivamente. Verificou-se resposta quadrática $(\mathrm{P}<0,01)$ para os consumos de MS, MO, FDN, PB e EE em kg/dia e em g/kg PV.

O maior consumo de MS ocorreu quando o teor de PB foi de $10,5 \%$, no qual foram obtidos os valores de $7,7 \mathrm{~kg} / \mathrm{dia}$ e 19,5 g/kg PV. Houve queda progressiva no consumo de MS com os aumentos subseqüentes do suplemento na dieta. Segundo Wilson et al. (1975), os metabólitos intermediários do catabolismo da uréia podem, em parte, ser responsáveis pela redução na ingestão de alimentos quando o teor de uréia na ração total está acima de $1 \%$. No entanto, Silva et al. (2001) observaram reduções lineares no consumo de MS quando níveis crescentes de uréia $(0,0 ; 0,7 ; 1,4$ e $2,1 \%$ ) foram adicionados a uma dieta com relação 60:40 volumoso:concentrado e sugeriram que o menor consumo foi ocasionado pelos efeitos metabólicos da uréia e pela menor aceitabilidade do alimento.

O consumo de $\mathrm{PB}$ aumentou linearmente $(\mathrm{P}<0,01)$ com a adição do suplemento contendo uréia, o que era esperado, em decorrência de sua infusão ruminal. Os coeficientes de variação (Tabela 3) foram baixos, enquanto os de determinação das equações de regressão $(0,91 ; 0,83 ; 0,92$ e 0,99) foram elevados, o que explica o efeito quadrático dos níveis protéicos da dieta sobre os consumos de MS, MO, FDN e $\mathrm{PB}$, respectivamente. As equações obtidas permitem estimar os níveis protéicos a serem usados nas dietas para obter respostas máximas de consumo de MS, MO, FDN e PB. Os valores observados representam os pontos críticos, uma vez que teores protéicos mais elevados comprometem o consumo de todos os nutrientes avaliados.

A redução do consumo de MS em níveis superiores aos 10,5\% de PB pode estar relacionada à perda energética pelo calor de fermentação e energia retida na formação de uréia hepática, gerada pelo excesso de compostos nitrogenados impostos ao metabolismo (Poppi \& McLennan, 1995) e pelo gasto energético para síntese hepática de uréia. Por outro lado, os aumentos de consumo verificados até o limite de 10,5\% PB evidenciam a importância e a prioridade dos compostos nitrogenados quando se suplementam animais 
Tabela 3 - Consumos de nutrientes das dietas experimentais

\begin{tabular}{|c|c|c|c|c|c|c|c|c|c|}
\hline Nutriente & \multicolumn{5}{|c|}{ Nível de proteína bruta da dieta (\%) } & CV (\%) & \multicolumn{3}{|c|}{ Efeito $^{1}$} \\
\hline \multicolumn{10}{|c|}{ Consumo diário (kg) } \\
\hline MS & 6,9 & 7,3 & 7,7 & 7,3 & 6,9 & 4,3 & NS & $*$ & NS \\
\hline MO & 6,5 & 6,8 & 7,3 & 6,8 & 6,4 & 4,3 & NS & $*$ & NS \\
\hline FDN & 5,6 & 5,9 & 6,2 & 5,8 & 5,4 & 4,2 & NS & $*$ & NS \\
\hline \multicolumn{10}{|c|}{ Consumo diário (g/kg PV) } \\
\hline MS & 17,5 & 18,7 & 19,5 & 18,4 & 17,3 & 4,6 & NS & $*$ & NS \\
\hline MO & 16,4 & 17,5 & 18,3 & 17,2 & 16,3 & 4,5 & NS & $*$ & NS \\
\hline FDN & 14,3 & 15,0 & 15,6 & 14,5 & 13,6 & 4,5 & NS & $*$ & NS \\
\hline РB & 1,1 & 1,6 & 2,1 & 2,3 & 2,6 & 6,8 & $*$ & $*$ & NS \\
\hline
\end{tabular}

$1 *=P<0,01 ; * *=P<0,05 ; N S=$ não-significativo $(P>0,05) ; \mathrm{L}, \mathrm{Q}$, e $\mathrm{C}=$ efeitos de ordem linear, quadrática e cúbica atribuídos aos níveis de proteína bruta das dietas, respectivamente.

Regressões: $Y_{C M S}(\mathrm{~kg} / \mathrm{dia})=2,4223+1,0030 \mathrm{~PB}-0,04791 \mathrm{~PB}^{2}\left(R^{2}=0,91\right) Y_{\mathrm{CMO}(\mathrm{kg} / \mathrm{dia})}=2,2602+0,9417 \mathrm{~PB}-0,04497 \mathrm{~PB}^{2}\left(R^{2}=0,83\right) Y_{\mathrm{CFDN}(\mathrm{kg} / \mathrm{dia})}=2,0700$ $+0,7960 \mathrm{~PB}-0,03899 \mathrm{~PB}^{2}\left(\mathrm{R}^{2}=0,92\right)$

$\mathrm{Y}_{\mathrm{CPB}(\mathrm{kg} / \mathrm{dia})}=-0,4769+0,1766 \mathrm{~PB}-0,00517 \mathrm{~PB}^{2}\left(\mathrm{R}^{2}=0,99\right)$

alimentados com volumoso de baixa qualidade. Nesta condição, o fornecimento de nitrogênio suplementar ao ambiente ruminal proporciona melhor condição de crescimento dos microrganismos e pode, inclusive, aumentar a taxa de degradação da fibra (FDN) (Lazzarini et al., 2006) e acelerar a remoção dos compostos indigestíveis e a taxa de reciclagem da fração sólida do rúmen.

Os coeficientes de digestibilidades da MS, MO, FDN e EE (Tabela 4) não foram afetados pela variação dos níveis de PB da dieta e apresentaram valores médios de 51,9; 54,2; 52,1 e 38,0\%, respectivamente. O coeficiente de digestibilidade da $\mathrm{PB}$ apresentou respostas linear $(\mathrm{P}<0,01)$ e quadrática $(\mathrm{P}<0,05)$, variando de $57,4 \%$, quando fornecido o feno $(6,3 \%$ $\mathrm{PB})$, a $81,7 \%$, quando utilizado o nível mais elevado de suplementação nitrogenada (14,8\% PB).

Koster et al. (2002), utilizando níveis reduzidos de uréia (0, 26 e $52 \mathrm{~g} / \mathrm{dia})$ associados ao feno de baixa qualidade (2,42\% de PB e 73,5\% de FDN), também não verificaram efeito da adição de uréia sobre a digestibilidade da MO e da FDN, cujos valores médios foram de 48,6 e 50,43\% respectivamente, próximos aos obtidos neste estudo. Silva et al. (2001) também não observaram efeito dos níveis crescentes de NNP sobre o comportamento digestivo dos nutrientes, embora tenham trabalhado com relação volumoso:concentrado de 60:40. Entretanto, de acordo com Kropp et al. (1977), alguns estudos comprovam redução na digestibilidade da MO com o uso de suplementos à base de uréia, principalmente quando o nitrogênio da uréia representou mais de $50 \%$ do equivalente protéico. Esses autores sugeriram que as limitações nos fatores de crescimento bacteriano, como peptídeos, aminoácidos e ácidos graxos de cadeia ramificada, poderiam reduzir a digestão e a produção microbiana.

Os valores de digestibilidade da MS e da MO reduziram de 53,7 para $50,0 \%$ e de 55,8 para $52,5 \%$, respectivamente, quando o teor protéico da dieta aumentou de 6,3 para $8,5 \%$ PB e se mantiveram nestes patamares até o nível de 12,6\% $\mathrm{PB}$, no qual elevaram novamente aos valores iniciais, quando a dieta atingiu $14,8 \%$ de $\mathrm{PB}$, ou seja, quando os consumos de MS e MO foram menores, os valores de digestibilidade de MS e MO foram mais elevados. A FDN, por sua vez, reduziu de 54,6 para 51,8\% quando o nível de PB da dieta elevou de $6,3 \%$ para $14,8 \%$, evidenciando que o ambiente ruminal foi mais favorável às bactérias proteolíticas em detrimento às celulolíticas à medida que elevou o nível de NNP nas dietas. Possivelmente a quantidade adicional de carboidratos ingeridos quando o consumo de MS foi mais elevado, associada ao fornecimento do suplemento nitrogenado, não foi suficiente para estimular o crescimento das bactérias fibrolíticas e acelerar a taxa de degradação dos carboidratos estruturais desse volumoso. Segundo Yokoyama \& Johnson (1993), quando a energia é o fator limitante, algumas espécies de bactérias não-fibrolíticas mudam sua rota metabólica para proporcionar maiores rendimentos de energia no processo de degradação ruminal, promovendo resultados mais favoráveis para a digestibilidade em situações de consumo de MS reduzido.

Os resultados de coeficiente de digestibilidade da PB diferiram dos obtidos por Silva et al. (2001) e Souza et al. (2003), que não encontraram diferenças significativas na digestibilidade da PB com a utilização crescente de uréia em 
Tabela 4 - Coeficientes médios de digestibilidade dos nutrientes das dietas experimentais

\begin{tabular}{|c|c|c|c|c|c|c|c|c|c|}
\hline & \multicolumn{5}{|c|}{ Nível de proteína bruta da dieta (\%) } & CV (\%) & \multicolumn{3}{|c|}{ Efeito $^{1}$} \\
\hline MS & 53,7 & 50,0 & 51,3 & 51,6 & 53,0 & 5,5 & NS & NS & NS \\
\hline FDN & 54,6 & 51,1 & 51,8 & 51,1 & 51,8 & 5,2 & NS & NS & NS \\
\hline PB & 57,4 & 66,9 & 73,6 & 77,3 & 81,7 & 4,0 & * & $* *$ & NS \\
\hline $\mathrm{EE}$ & 40,3 & 35,1 & 35,6 & 39,2 & 39,7 & 20,3 & NS & NS & NS \\
\hline
\end{tabular}

$1 *=P<0,01 ; * *=P<0,05 ; N S=$ não-significativo $(P>0,05) ; L, Q$ e $C=$ efeitos de ordem linear, quadrática e cúbica relativos aos níveis de aumento da proteína bruta na dieta, respectivamente.

dietas com $50 \%$ de silagem de milho ou $70 \%$ de silagem de sorgo na MS, respectivamente. Church \& Santos (1981), no entanto, observaram digestibilidades negativas da PB quando dietas de palhadas de trigo sem suplementação foram fornecidas aos bovinos. Contudo, esses autores observaram aumento na digestibilidade da PB com a suplementação protéica e atribuíram o resultado à intensa reciclagem da uréia no organismo do animal.

Não houve efeito dos níveis de nitrogênio não-protéico (NNP) sobre os coeficientes de digestibilidade da FDN, que variaram de 51,1 a 54,6\%, evidenciando pouca alteração na atividade fibrolítica dos microrganismos ruminais, mesmo em condições favoráveis às bactérias ruminais, como NNP, enxofre, caseína e ácidos graxos de cadeia ramificada. Esses resultados aparentemente contrariam as pressuposições anteriormente apresentadas. Entretanto, a dinâmica da fermentação envolve os processos de degradação ruminal e de trânsito e devem ser avaliados de forma integrada. À medida que acelera a utilização dos compostos potencialmente digestíveis pelos microrganismos, reduz-se o tempo necessário para as partículas diminuírem e atingirem a faixa de densidade específica e conseqüentemente serem removidas para o trato posterior (Allen, 1996). Pela relação consumo e digestibilidade (Tabelas 3 e 4), tanto o consumo de MS quanto o de MO elevaram com o aumento do nível de PB da dieta (de 6,3 até 10,5\% PB), enquanto a digestibilidade da MS e da MO reduziu, numericamente, no mesmo intervalo. Os valores mais elevados de digestibilidade da MS (53,7\% e $53,0 \%)$ e da $\mathrm{MO}(55,8$ e $55,3 \%)$ ocorreram quando os consumos foram inferiores (6,9 kg de MS/dia e 6,5 kg de MO/ dia e 6,4 kg de MO/dia), ou seja, nos níveis de 6,3\% e 14,8\% de PB da dieta, respectivamente. A provável justificativa para esses achados foi o efeito de enchimento do rúmen, que limitou fisicamente o animal de expressar seu potencial máximo de consumo (Mertens, 1994), e o maior tempo de permanência da fração fibrosa, que, por ser de baixa qualidade, não disponibilizou nutrientes suficientes para aumentar a digestibilidade.

O nível de 10,5\% PB foi o ponto crítico para a obtenção de resposta máxima para o consumo de 7,7 kg MS/dia e 7,2 kg MO/dia (Tabela 5). Para a FDN, os valores foram de 10,21\% PB e 6,13 kg FDN/dia. Quando expresso em g/kg PV ,

Tabela 5 - Estimativas de parâmetros de regressão, posição e resposta estimada para o ponto crítico para as variáveis estudadas em relação ao nível de proteína bruta na dieta ingerida (\% da MS)

\begin{tabular}{|c|c|c|c|c|c|c|}
\hline & \multicolumn{3}{|c|}{ Estimativa de parâmetros de regressão } & $\mathrm{R}^{2}$ & \multicolumn{2}{|c|}{ Ponto crítico } \\
\hline \multicolumn{7}{|c|}{ Consumo diário (kg) } \\
\hline $\mathrm{MS}^{2}$ & 2,4223 & 1,0030 & $-0,04791$ & 0,91 & 10,47 & 7,672 \\
\hline $\mathrm{MO}^{3}$ & 2,2602 & 0,9417 & $-0,04497$ & 0,83 & 10,47 & 7,190 \\
\hline $\mathrm{FDN}^{4}$ & 2,0700 & 0,7960 & $-0,03899$ & 0,92 & 10,21 & 6,133 \\
\hline \multicolumn{7}{|c|}{ Consumo diário (g/kg PV) } \\
\hline $\mathrm{MS}^{2}$ & 7,6012 & 2,2673 & $-0,10957$ & 0,94 & 10,35 & 19,33 \\
\hline $\mathrm{MO}^{3}$ & 7,0997 & 2,1290 & $-0,10286$ & 0,91 & 10,35 & 18,12 \\
\hline $\mathrm{FDN}^{4}$ & 6,4356 & 1,7940 & $-0,08919$ & 0,91 & 10,06 & 15,46 \\
\hline $\mathrm{PB}^{5}$ & - 1,1365 & 0,4336 & $-0,01251$ & 0,99 & 17,33 & 2,62 \\
\hline
\end{tabular}

Digestibilidade (\%)

$\mathrm{PB}^{7}$

19,2890

7,4866

$-0,22214$

0,99

16,85

82,37 
o comportamento foi similar, com valores de 10,35\% PB e 19,33 g MS/kg PV e 18,12 g MO/kg PV. Valor protéico de ponto crítico (10,5\% de $\mathrm{PB}$ ) semelhante ao obtido neste trabalho foi observado por Sampaio et al. (2006) em novilhas mestiças alimentadas com feno de Brachiaria decumbens e quantidades crescentes de suplemento contendo uréia, sulfato de amônio e albumina. Entretanto, para os consumos de $\mathrm{PB}$ em kg/dia, g/kg PV e em porcentagem, os pontos críticos foram de 17,08; 17,33 e 16,85\% de PB e se situaram fora da faixa de controle experimental estudada.

Associando os resultados de consumo e digestibilidade obtidos, verificou-se que o suplemento fornecido em quantidade suficiente para elevar a dieta até os níveis de 10,5\% de PB forneceu nitrogênio não-protéico aos microrganismos ruminais e estimulou o consumo de substratos energéticos da forragem, mas não foi capaz de aumentar a digestibilidade. Doses excessivas de nitrogênio ocasionam maiores perdas energéticas, em decorrência do aumento da produção de calor de fermentação e do gasto de energia para a produção de uréia imposta ao metabolismo do animal para prevenir a intoxicação e reduzem a eficiência energética e o consumo de matéria seca do volumoso.

\section{Conclusões}

Os compostos nitrogenados não-protéicos têm função prioritária quando bovinos de corte são alimentados com pastos de baixa qualidade. A suplementação da dieta em quantidades que permitam elevar seu nível protéico próximo de 10,5\% de PB maximiza o suprimento energético fornecido pelo volumoso.

\section{Literatura Citada}

ALLEN, M.S. Physical constrains on voluntary intake of forages by ruminants. Journal of Animal Science, v.74, n.10, p.30633075, 1996.

ARROQUY, J.I.; COCHRAN, R.C.; WICKERSHAM, T.A. et al. Effects of type of supplemental carbohydrate and source of supplemental rumen degradable protein on low quality forage utilization by beef steers. Animal Feed Science and Technology, v.115, n.3-4, p.247-263, 2004.

CAMPOS, F.P.; SARMENTO, P.; NUSSIO, L.G. et al. Efeito da associação de fontes e níveis de concentrados sobre a degradabilidade do capim-elefante cv. Napier, monitorado pelo sistema in vitro/gás. In: REUNIÃO ANUAL DA SOCIEDADE BRASIlEIRA DE ZOOTECNIA, 39., 2002, Recife. Anais... Recife: Sociedade Brasileira de Zootecnia, 2002. (CD-ROM).

CAPPELLE, E.R.; VALADARES FILHO, S.C.; COELHO DA SILVA, J.F. et al. Estimativas do valor energético a partir de características químicas e bromatológicas dos alimentos. Revista Brasileira de Zootecnia, v.30, n.6, p.1837-1856, 2001.

CHURCH, D.C.; SANTOS, A. Effect of graded levels of soybean meal and of a no protein nitrogen molasses supplement on consumption and digestibility of wheat straw. Journal of Animal Science, v.53, p.1609-1615, 1981.
EGAN, J.K.; DOYLE, P.T. Effect of intraruminal infusion of urea on the response in voluntary feed intake by sheep. Australian Journal of Agriculture Research, v.36, p.483-495, 1985.

EUCLIDES, V.P.B. Desempenho animal em pastagens. In: CURSO DE PASTAGENS 1997, Campo Grande. Palestras... Campo Grande: EMBRAPA-CNPGC, 1997. (não-paginado).

KÖSTER, H.H.; WOODS, B.C.; COCHRAN, R.C. et al. Effect of increasing proportion of supplemental $\mathrm{N}$ from urea in prepartum supplements on range beef cow performance and on forage intake and digestibility by steers fed low quality forage. Journal of Animal Science, v.80, n.6, p.1652-1662, 2002.

KROPP, J.R.; JOHNSON, R.R.; MALES, J.R. et al. Microbial protein synthesis with low quality roughage ration: isonitrogenous substitution of urea for soybean cake. Journal of Animal Science, v.46, p.837-843, 1977.

LENG, R.A. Supplementation of tropical and subtropical pastures for ruminant production. In: GILCHRIST, F.M.C.; MACKIE, R.I. (Eds.) Herbivore nutrition in the subtropics and tropics. Craighall: The Science Press, 1984. p.129-144.

LAZZARINI, I.; DETMANN, E.; SAMPAIO, C.B. et al. Dinâmica de degradação ruminal in situ da fibra em detergente neutro em bovinos alimentados com forragem de baixa qualidade suplementados com níveis crescentes de compostos nitrogenados. In: REUNIÃO ANUAL DA SOCIEDADE BRASILEIRA DE ZOoteCniA, 43., 2006, João Pessoa. Anais... João Pessoa: Sociedade Brasileira de Zootecnia, 2006. (CD-ROM).

LUCAS, H.L. Extra-period latin-square change-over designs. Journal of Dairy Science, v.40, n.3, p.225-239, 1957.

MAGALHÃES, K.A.; VALADARES FILHO, S.C.; VALADARES, R.F.D. et al. Níveis de uréia em substituição ao farelo de soja na dieta de novilhos de origem leiteira em confinamento. 1. Desempenho. In: REUNIÃO ANUAL DA SOCIEDADE BRASIlEIRA DE ZOOTECNIA, 39., 2002, Recife. Anais... Anais... Recife: Sociedade Brasileira de Zootecnia, 2002. (CD-ROM).

MERTENS, D.R. Regulation on forage intake. In: FAHEY JR, G.C.; COLLINS, M.; MERTENS, D.R. et al. (Eds) Forage quality, evaluation, and utilization. Madison: University of Nebraska, 1994. p.450-483.

MYERS, R.H. Classical and modern regression with applications. Boston: PWS-KENT Publishing Co, 1990. 488p.

ORSKOV, E.R. The in situ technique for the estimation of forage degradability in ruminants. In: GIVENS, D.I.; OWEN, E.; AXFORD, R.F.E. et al. (Eds) Forage evaluation in ruminant nutrition. London: CAB International, 2000. p.175-188.

PAULINO, M.F. Suplementos múltiplos para recria e engorda de bovinos em pastagens. In: CONGRESSO NACIONAL DE ESTUDANTES DE ZOOTECNIA, Viçosa, MG. Anais... Viçosa, MG: CONEZ, 1998. p.173-188.

PAULINO, M.F.; REHFELD, O.A.M.; RUAS, J.R.M. et al. Alguns aspectos da suplementação de bovinos de corte em regime de pastagem durante a época seca. Informe Agropecuário, n.89, p.28-31, 1982.

POPPI, D.P.; McLENNAN, S.R. Protein and energy utilization by ruminants at pasture. Journal of Animal Science, v.73, n.1, p.278-290, 1995.

RENNÓ, L.N.; VALADARES FILHO, S.C.; PAULINO, M.F. et al. Níveis de uréia na ração de novilhos de quarto grupos genéticos: Consumo. In: REUNIÃO ANUAL DA SOCIEDADE BRASILEIRA DE ZOOTECNIA, 40, 2003, Santa Maria. Anais... Santa Maria: Sociedade Brasileira de Zootecnia, 2003. (CD-ROM).

RIBEIRO JR., J.I. Análises estatísticas no SAEG. Viçosa, MG: Universidade Federal de Viçosa, 2001. 301p.

RUSSELL, J.B.; O’CONNOR, J.D.; FOX, D.G. et al. A Net Carbohydrate and Protein System for evaluating cattle diets. I. Ruminal fermentation. Journal of Animal Science, v.70, n.11, p.3551-3561, 1992.

SAMPAIO, C.B.; DETMANN, E.; LAZZARINI, I. et al. Consumo e digestibilidade em bovinos alimentados com forragem de baixa 
qualidade recebendo níveis crescentes de compostos nitrogenados suplementares. In: REUNIÃO ANUAL DA SOCIEDADE BRASILEIRA DE ZOOTECNIA, 43., 2006, João Pessoa. Anais... João Pessoa: Sociedade Brasileira de Zootecnia, (2006) CD-ROM. Nutrição de Ruminantes.

SILVA, R.M.N.; VALADARES, R.F.D.; VALADARES FILHO, S.C. et al. Uréia para vacas em lactação. 1. Consumo, digestibilidade, produção e composição do leite. Revista Brasileira de Zootecnia, v.30, n.5, p.1639-1649, 2001.

SILVA, D.J.; QUEIROZ, A.C. Análise de alimentos: métodos químicos e biológicos. 3.ed. Viçosa, MG: Editora UFV, 2002. 253p.

SOUZA, V.G.; PEREIRA, O.G.; VALADARES FILHO, S.C. et al. Consumo, digestibilidade e parâmetros ruminais de bovinos de corte recebendo dietas com diferentes níveis de uréia. In: REUNIÃO ANUAL DA SOCIEDADE BRASILEIRA DE ZOOTECNIA, 40., 2003, Santa Maria. Anais... Santa Maria: Sociedade Brasileira de Zootecnia, 2003. (CD-ROM).

STEEL, R.; TORRIE, J.H.; DICKEY, D.A. Principles and procedures of statistics. A biometrical approach. New York: McGrawHill Co., 1997. 666p.

WILSON, G.; MARTZ, F.A.; CAMPBELL, J.R. et al. Evaluation of factors responsible for reduced voluntary intake of urea for ruminants. Journal of Animal Science, v.41, n.5, p.14311437, 1975.

YOKOYAMA, M.T.; JOHNSON, K.A. Microbiologia del rumen e intestine In: CHURCH, C.D. (Ed.) El rumiante fisiología digestiva y nutrición. Zaragoza: Acribia, 1993. p.137-157. 